\title{
ENVELHECER: uma transformação natural, aos olhos da microscopia
}

\author{
AGING: a natural transformation in a microscopic view.
}

\author{
Bismarck Ascar Sauaia1, Bruno Bavaresco Gambassi²
}

Resumo: O processo de envelhecimento retrata um conjunto de transformações celulares e teciduais, que o organismo deve apresentar de forma progressiva e natural. Objetivo: Reconhecer as modificações microscópicas dos diferentes órgãos no envelhecimento humano, assim como fenômenos condicionados por reações e respostas do organismo à perda da celularidade, entre os quais a diminuição crescente dos processos metabólicos de síntese celular, adsorção de superfícies e catálise química. Método: foram selecionadas, para leitura microscópica, 1500 lâminas permanentes, do acervo do LMF da Faculdade de Medicina da Universidade Ceuma. São Luís, MA, com cortes de diferentes órgãos, todos processados por inclusão em parafina e coloridos com Hematoxilina-eosina. A leitura ocorreu duas vezes por semana, por 180 dias, em microscopia de luz, com o uso de lentes objetivas de 40X e oculares de 20X. Resultados: foi observada uma perda progressiva de celularidade; afastamento do corpo celular em neurônios de áreas encefálicas; redução das modificações de membranas nas superfícies mucosas; aumento das ocupações intersticiais por conjuntivos de preenchimento e depósitos de gordura; perda proteica em áreas esqueléticas de tendões e ligamentos; fibrose muscular, ateromas, congestão vascular. Conclusões: o envelhecimento é condição natural, assim como as respostas fisiológicas mais lentas e menos duradouras que envolvem os movimentos de órgãos e, até do próprio organismo, com redução do equilíbrio esquelético e comunicação nervosa, flacidez dos conjuntivos de preenchimento.

Palavras-chave: Idoso. Envelhecimento. Qualidade de vida.

\begin{abstract}
Introduction: The aging process portrays a set of cell and tissue changes, the body must provide a progressive and natural way. Objectives: Recognize the microscopic changes of different organs in human aging, as the phenomena conditioned by body's reactions and responses to the loss of cellularity, among which the progressive reduction of metabolic processes in cellular synthesis, surface adsorption and chemical catalysis. Method: We selected, for microscopy analysis, 1500 permanent samples from the collection of Morphofunctional Lab of the Faculty of Medicine, CEUMA University, São Luís, MA, with views of different organs, all of them prepared using paraffin inclusion technique and stained with haematoxylin-eosin. The analysis was performed twice a week, for 180 days, in optical microscope, using 40x objective lens and 20x ocular ones. Results: We observed a progressive loss of cellularity, isolation of cell body in encephalic neurons; reduction of membrane changes in mucosal surfaces; increase of interstitial filling by connective and adipose tissues; protein loss in tendons and ligaments; muscular fibrosis; atheromas; and vascular congestion. Conclusions: aging is a natural condition, as the slower and less permanent physiological responses which involves organs and body movements, with reduction of skeletal equilibrium, communication between nerve cells and sagging of connective tissues.
\end{abstract}

Keywords: Elder. Aging. Life quality.

1 - Doutorando em Biotecnologia - UNICEUMA

2 - Docente - UNICEUMA

Rev. de Investig, Biomédica, São Luís, 7:91-97. 2015 


\section{Introdução}

A partir da terceira década de vida 0 ser humano reduz em aproximadamente $50 \%$ a sua celularidade e, a partir da quinta década de vida a redução da celularidade pode alcançar $70 \%$; 0 que gera um aumento dos espaços intersticiais preenchidos, então por glicoproteínas, uma condição predisponente às roturas dos tecidos de sustentação esqueléticas que unem ossos e ossos a músculos.

As observações e leituras de tecidos humanos e de animais mamíferos em diferentes momentos do crescimento e desenvolvimento, cuja semelhança histológica advém da similaridade genética entre as espécies, aquelas mais próximas evolutivamente do homem (roedores, canídeos, etc.), reflete uma transformação natural.

Os tecidos de revestimento apresentam-se com polimorfismo celular, de alta capacidade regenerativa, originados a partir de uma mácula germinativa que é capaz de recompor e substituir células envelhecidas ou que simplesmente descamaram por processos naturais, ainda quando 0 corpo fica exposto às alterações de temperatura e luminosidade ${ }^{1}$.

Originados dos tecidos de superfície por diferenciação celular e multiplicação mitótica, invaginando para as áreas subjacentes, onde se definem as estruturas secretoras das diferentes formações glandulares ${ }^{2}$.

Os tecidos conjuntivos reportam a maior composição diferenciada do organismo humano, estabelecendo-se desde áreas de preenchimento, sustentação esquelética, sustentação dos arcabouços de paredes moles, formações de placas, discos e arcos de cartilagens, bainhas e envoltórios, septos e trabéculas; nas matrizes produtoras de células para o sangue; até no acolchoamento de paredes de órgãos ${ }^{3}$.

As formações hemapoéticas que constituem a medula óssea se encarregam de produzir uma série de células originadas a partir de fenômenos orgânicos naturais, entre eles destacam-se a osteoblastia de alta atividade, quando do organismo jovem e, diminuindo gradualmente com o estado de envelhecimento. $O$ contrário ocorre com a osteoclastia no controle da deposição mineral na matriz óssea e da reabsorção $0^{3 ; 4}$.

A medula óssea vermelha também é fonte de outras formações, como células de cartilagens, hemácias, leucócitos e plaquetas ${ }^{4}$.

Os tecidos linfáticos constituintes do parênquima do baço, timo, linfonodos e tonsilas, são capazes de produzir e madurecer leucócitos, produzir anticorpos, garantindo o equilíbrio imunitário do organismo com o meio ${ }^{5}$.

Algumas células, especialmente conjuntivas, são capazes de exercer funções as quais não seriam, necessariamente, aquelas designadas por origem embrionária, é o caso dos mioblastos ou miofibroblastos ${ }^{6}$.

A musculatura esquelética que estrutura arcabouços e de sobre ossos, responde à função em qualquer idade, garantindo autonomia e mobilidade ao esqueleto, sempre associada a tecido adiposo e frouxo ${ }^{7}$. 
A fibrose muscular, principalmente por desoxigenação e envelhecimento celular, representa a maior causa de revascularização cardíaca, associado a obstrução por ateroma da parede dos vasos ${ }^{8}$.

Os tecidos nervosos apresentam corpos celulares e grandes prolongamentos de fibras comunicando e transportando estímulos ao longo do organismo humano ${ }^{9 ; 10}$.

Os corpos celulares dos neurônios de diferentes formações destacam-se à luz da microscopia nas áreas cinzentas do encéfalo, constituindo camadas multipolar, multiforme e piramidal no cérebro; unipolar no cerebelo. Corpos celulares são evidentes em áreas cinzentas da medula nervosa, sem constituir qualquer camada ${ }^{11 ; 12}$.

As modificações observadas à luz da microscopia e, comparadas com respostas fisiológicas de humanos em diferentes faixas etárias, possibilitou 0 relato da presente teoria.

\section{Metodologia}

A pesquisa incluiu 1500
lâminas selecionadas
processadas no laboratório de
histologia, pelo método de Inclusão
em parafina e coloração com
Hematoxilina - Eosina. Todas as
lâminas fazem parte do acervo do
Laboratório Morfofuncional (LMF) da
Faculdade de Medicina da
Universidade Ceuma de São Luís,
Maranhão, onde ocorreram as
leituras em microscópio de luz com
lentes objetivas de 40X e oculares
de 20X.

As lâminas foram doadas de peças anatômicas de cadáveres do laboratório de Anatomia da mesma universidade e retiradas quando da dissecção dos corpos.

Foram excluídas lâminas com cortes espessos, acima de 7 micra e com dificuldade na leitura histológica por diminuição da translucidez da imagem em lente microscópica e, incluídas na seleção, lâminas com cortes até 4 micras e boa translucidez de imagens.

A pesquisa faz parte de um projeto maior, sobre qualidade de vida, aprovada pelo Comitê de Ética em Pesquisa com Humanos do Hospital Universitário, com parecer consubstanciado ํㅡ 276/2011.

\section{Resultados}

A partir de estudos
histológicos leitura
microscópica de tecidos de
diferentes órgãos humanos, foram
observados e relatados em
parágrafos situações capazes de
definir e justificar um estado de
envelhecimento natural.

Foram observados à luz da microscopia:

01. As áreas intersticiais $\mathrm{e}$ extracelulares, de matriz são ocupadas facilmente por células de gordura de origem endógena, de suas reservas e preenchidas por lipídios da ingesta;

02. Nos espaços de lâmina própria, ocorre uma redução da qualidade proteica, tanto na espessura e complacência das fibras elásticas, como na sustentação da rede reticular de base matricial;

03. O estroma ovariano reporta a mais bela estrutura com condições de definir a idade do organismo por perda de sua celularidade e redução 
da capacidade reprodutiva do organismo;

04. O Aumento do halo, por redução do número de dendritos do corpo celular e consequente diminuição progressiva das comunicações neuronais;

05. Redução do número e aumento do espaço entre as formações celulares, no interstício nervoso, consequente multiplicação de pequenos e proximidade vascular, fragilizando a matriz tecidual;

06. Redução do número de fibras musculares, especialmente lisas, em estruturas de paredes, com consequente fibrose proteica dos espaços conjuntivos, fato que reduz o estado de complacência da parede, tornando a atividade metabólica e/ou fisiológica dependente e lenta;

07. Nas formações alveolares há um aumento do espaço de luz e uma redução do lúmen ductal, com consequente diminuição da complacência da parede, decorrente da impossibilidade de formação de miofibroblastos e da perda com a idade da atividade mióide de células remanescentes;

08. Nas formações esqueléticas há uma diminuição crescente e progressiva proporcional à idade, do número de osteoblastos com consequente surgimento de osteócitos da periferia para o centro do córtex ósseo; aumento e sobreposição de células de reabsorção mineral, que se apresentam em fila indiana à luz dos canais e no limiar da matriz óssea com a medula;

09. No interstício mineral da epífise óssea ocorre espessamento das espículas, enquanto que na diáfise ocorre uma redução das formações trabeculares, tornando o córtex mais frágil que a cabeça do osso;

10. À luz dos sistemas nutricionais da matriz óssea que comunica a medula, aumenta progressivamente com a idade no córtex e apesar de morfologicamente não se evidenciar tais formações na epífise; ao microscópio são bem definidas no interior das espículas, mantendo a luz cada vez mais reduzida com a idade;

11. Ao nível do sistema vascular, ocorre uma diminuição das fibras elásticas, perda na sustentação da túnica média das artérias; fragilidade endotelial comprometendo o fluxo sanguíneo às extremidades do corpo com consequente alteração da pressão arterial, definindo um estado de hipertensão;

12. Ao nível cardíaco, verifica-se uma fibrose conjuntiva, perda de miofibroblastos, deposição de gordura no interstício muscular e interior vascular, com comprometimento da atividade miometrial, do fluxo circulatório e pressão arterial;

13. Ao nível estrutural e histológico, as cartilagens elásticas demonstram um aumento progressivo, com a idade, das divisões mitóticas evidenciadas na leitura microscópica de células com binucleações;

14. Nas formações endocondrais ocorre um estreitamento tecidual e uma linha proteica de deposição na matriz, circundando cada conjunto alinhado de células;

15. Nas formações hialinas, ocorre uma mudança proteica depositada, apresentando-se à luz da microscopia, mais clara, rosa ou avermelhada endurecidas ou enrijecidas; redução das formações 
musculares diminuindo $a$ parede do órgão;

16. As capas conjuntivas de ossos, músculos e cartilagens colabam às estruturas no limiar de cada matriz, comprimindo os ramos nervosos, diminuindo a resposta e o estado dinâmico de equilíbrio do organismo.

Assim ocorre a

transformação natural do organismo humano.

\section{Discussão}

Apesar do número reduzido de bibliografias que retratam 0 estado microscópico do envelhecimento natural do organismo humano, pesquisadores afirmaram que 0 envelhecimento celular decorre da exposição do corpo às alterações de temperatura e luminosidade, ao longo da vida; fatores de diminuição precoce da celularidade, envelhecimento e morte celular ${ }^{1}$.

Os tecidos conjuntivos representam a maior composição diferenciada do organismo humano ${ }^{3}$. Por ocuparem áreas de preenchimento, sustentação esquelética, sustentação dos arcabouços de paredes moles, formações de placas, discos e arcos de cartilagens, bainhas e envoltórios, septos e trabéculas; nas matrizes produtoras de células para o sangue; até no acolchoamento de paredes de órgãos, também representam as áreas de maiores modificações com o envelhecimento tecidual por redução celular e delgadas formações proteicas.

Fenômenos como a osteoblastia de alta atividade, quando do organismo jovem e, osteoclastia no controle da deposição mineral na matriz óssea e, da reabsorção ${ }^{3 ; 4}$. São capazes de definir um aumento da luz dos canais na matriz óssea, assim como uma maior concentração de células de reabsorção no limiar dessa matriz com a medula óssea, como observados na presente pesquisa.

A fibrose muscular, condicionada pelo envelhecimento celular e deposição de colágeno, representa a maior causa de revascularização cardíaca, associado à obstrução por ateroma da parede dos vasos ${ }^{8}$. fato relatado em nossas observações microscópicas quando são definidos espaços de deposição de proteína e redução das fibras musculares na extensão do miocárdio, assim como uma crescente deposição de anéis de gordura no interior vascular.

Os tecidos nervosos apresentam corpos celulares e grandes prolongamentos de fibras comunicando e transportando estímulos ao longo do organismo humano ${ }^{9 ; 10}$. Como observamos também na pesquisa, os corpos neuronais, constituindo ou não camadas são evidentes em áreas cinzentas do encéfalo ${ }^{11 ; 12}$. Com redução de formações dendríticas nos corpos celulares favoravelmente definem área de "halo" ao redor do pericário neuronal, aumentado proporcionalmente com a idade.

\section{Conclusão}

Sobre o estado natural de envelhecimento, foi possível concluir que: (a) o envelhecimento é condição natural do organismo humano; (b) há uma perda progressiva do número de células 
constituintes dos diferentes tecidos e regiões de órgãos do organismo humano; (c) respostas fisiológicas mais lentas e menos duradouras, tais como aquelas que envolvem os movimentos do organismo, equilíbrio esquelético e comunicação nervosa, se dão pela perda da celularidade, afastamento do corpo celular e redução das modificações de membranas capazes de manter tais comunicações; (d) a flacidez dos conjuntivos de preenchimento e a fragilidade dos tecidos que unem ossos e ossos a músculos, decorrem da perda proteica e celular, assim como da deposição de gordura de origem endógena ou por ingesta; (e) existe uma relação direta entre 0 estado patológico crônico e a maior idade do organismo humano; (f) 0 envelhecimento natural do organismo humano deve ser acompanhado de uma prática esportiva e ou atividade física, assim como uma dieta alimentar balanceada, garantindo os nutrientes essenciais, redução de radicais livres, gordura saturada e baixa toxidade, prolongando 0 estado vital adaptativo da troca de celularidade nos diferentes órgãos de sua composição; (g) a biologia celular do envelhecimento não está diretamente relacionada à cronologia do organismo.

\section{Referências}

1. Glerean, A. \& Simões, M. J. Fundamentos de Histologia para Estudantes da Área da Saúde. 1a ed. São Paulo: Santos Ltda; 2007.
2. Junqueira, L. C. \& Carneiro, J. Histologia Básica - Texto e Atlas. 11르 Ed. Rio de Janeiro: Guanabara Koogan; 2012.

3. Kierszenbaum, A.L. Histologia e Biologia Celular - Uma Introdução à Patologia. $2^{\underline{a}}$ ed. São Paulo: ELSEVIER; 2008.

4. Leslie, P. Gartner; James, L. Hiatt. Tratado de Histologia. $2^{\mathrm{a}}$ ed. Rio de Janeiro: Guanabara Koogan; 2008.

5. Mariano, V. P. Noções Básicas de Citologia, Histologia, Anatomia e Fisiologia Humana. $1^{\underline{a}}$ ed. São Paulo: Ltr; 2008.

6. Piezzi, R.S.; Fornés, M.W. Novo Atlas de Histologia Normal de Di Fiore. Rio de Janeiro: Guanabara Koogan; 2008.

7. Ross, M.H. \&Pawlina, W. Histologia. Texto e Atlas, em correlação com a biologia celular molecular. 6 ${ }^{\mathbf{a}}$ ed. Rio de Janeiro: Guanabara Koogan; 2010.

8. Sauaia, A. L. P. \&Sauaia, B. A.. Súmula de Cortes Histológicos em Tecido Animal: pequeno atlas de histologia. $1^{\underline{a}}$ ed. São Luís: Bellas Artes, UNICEUMA; 2007.

9. Sobota. Histologia. Atlas Colorido de Citologia, Histologia e Anatomia Microscópica Humana. Envelhecer: uma transformação natural 93 Rev. Investig, Bioméd., São Luís, 1:87-93. 2015 Editora e Revisão de UlrichWelsch. $7^{a \underline{a}}$ ed. Rio de Janeiro: Guanabara Koogan; 2010. 
10. Stevens, A. \&Lowe, J. Histologia Humana. $2^{\underline{a}}$ ed. Rio de Janeiro: Manole; 2005.

11. W Heater's. Histologia Funcional. Texto e Atlas em Cores. 1a ed. São Paulo: ELSEVIER; 2007.

12. Young, B.; Heath, J.W. HistologiaFuncional. Texto e Atlas em Cores. $5^{\mathrm{a}}$ ed. Rio de Janeiro: Guanabara Koogan; 2010. 